\title{
Cone Dosage Form
}

National Cancer Institute

\section{Source}

National Cancer Institute. Cone Dosage Form. NCI Thesaurus. Code C42900.

A solid with a shape bounded by a circular base converging upon a single vertex. 